\title{
Use of PG-E 2 Gel for Cervical Ripening in Labour Induction
}

\section{Snehal Deshmukh ${ }^{1}$, Mugdha L Jungari ${ }^{2}$, Urvashi Shrama ${ }^{3}$}

Section: Healthcare

Sci. Journal Impact

Factor: 6.1 (2018)

ICV: 90.90 (2018)

Scopus'

\begin{abstract}
Senior Resident Datta Meghe Medical College, Shalinitai Meghe Hospital And research Centre, (DMIMSU), Nagpur-441110; ${ }^{2}$ Associate Professor, Department of Obstetrics and Gynecology, Datta Meghe Medical College, Shalinitai Meghe Hospital and Research Centre, (DMIMS) Nagpur-44m110; ${ }_{3}^{3}$ Assistant Professor Dept. of Obstetrics and Gynecology, Jawaharlal Nehru Medical College, Datta Meghe Institute of Medical Sciences, Sawangi, Wardha-442001.
\end{abstract}

\section{ABSTRACT}

Continuing a woman's pregnancy allows her cervix to remain closed and strong, and her uterus to remain calm and not contracting. There is a need to reverse both of these conditions to initiate labour. Cervix includes a small smooth muscle and mainly connective tissue with collagen as its key component and it must ripen as it becomes soft and pliable.

Prostaglandins play a significant role in the process of cervical maturation and labour initiation. Prostagladin E2 intracervical gel contains $0.5 \mathrm{mg}$ of dinoprostone and induces collagen breakdown, dispersion, fluid absorption by stromal tissues and successful cervical maturation for labor induction when applied locally.

Materials and Methods: 70 antenatal patients who fulfilled the inclusion criteria were studied. Group 1 had patients who required a single dose of PGE2 gel and group 2 had patients who required a second dose of PGE2 gel.

Results and Observation: Group 1 had 56 patients requiring a single dose of dinoprostone gel and group 2 had 14 patients requiring a second dose of dinoprostone gel for induction. The common indication for induction of labour was postdatism (45.71 $\%)$, The mean bishop score at the time of induction was 1.9. The improvement in mean bishops score at 6 and 12 hours in group 2 is just 2 as compared to 7.02 in group 1, The overall mean induction delivery time was 21.45 hours. The incidence of normal delivery was $74.28 \%$ and caesarean section rate in our study was $21.45 \%$. The common complications that occurred were vomiting $(7.14 \%)$, diarrhea $(5.71 \%)$.

Conclusion: PGE2 GEL is a safe and effective method for the induction of labour. The success of induction depends upon the cervical status. It increases the chances of a vaginal delivery without increasing maternal and neonatal morbidity.

Key Words: PG-E2, Cervical ripening, Labour, Induction

\section{INTRODUCTION}

Modern obstetrics aim to improve maternal and fetal safety during antenatal period as well as parturition. The purpose of labor induction is to achieve safe vaginal delivery.

Labor induction is a procedure done after 28 weeks of gestation, intended to gradually induce uterine contractions resulting in the gradual effacement and dilatation of the cervix and culminating in vaginal delivery. The clinical necessity for labour induction emerges from conditions in which the result of the pregnancy in question is assumed to be safer if it is medically interrupted, rather than left to follow its normal path. The performance of induction largely depends on the conformity and structure of the cervix ${ }^{1}$. Therefore, the unripe cervix remains a well-recognized impediment to ef- fective labor induction. At the end of pregnancy a sequence of complex metabolic, physiological and physical processes cascade, culminating in delivery. The neuroendocrine pathways, humoral transmission, steroids, and local hormones modulate many events. The cervix becomes smooth, short with decreased cervical resistance during the transition to the start of labour. This cycle is called "cervical ripening ". The final successful outcome of induction depends on the degree of the pre-labor changes ${ }^{2}$

A. Calder $(1980)^{3}$ showed that prostaglandins essentially mature the cervix in two ways.

1. They induce collagen breakdown

2. They alter the hydration of tissue and the binding of collagen by altering the composition of glycosaminoglycan / proteoglycan. Glycosaminogly-

\section{Corresponding Author:}

Dr. Snehal Deshmukh, Senior Resident, Department of Obstetrics and Gynecology, Datta Meghe Medical College, Shalinitai Meghe Hospital and Research Centre, (DMIMS) Nagpur-441110; Email: deshmukhsnehal06@gmail.com

ISSN: 2231-2196 (Print)

Received: 02.06 .2020
ISSN: 0975-5241 (Online)

Revised: 25.06 .2020
Accepted: 07.07.2020
Published: 21.07 .2020 
cans are strongly hydrophilic and improve hydration in the tissue. Water content in non-pregnant cervix is $80 \%$ and it rises to $86 \%$ in pregnant cer$v^{2}{ }^{4}$. Thus they destabilize the fibrils of collagen and foster maturation. Chondratin sulphate and its epimer dermatin sulphate are the most common glycosaminoglycans in the cervix ${ }^{5,6}$

Prostaglandin E2 intracervical gel contains $0.5 \mathrm{mg}$ of dinoprostone and induces collagen breakdown, dispersion, fluid absorption by stromal tissues and successful cervical maturation for labor induction.

\section{MATERIAL AND METHODS}

The present retrospective study was carried out in the Dept. of OBGY at Datta Meghe Medical College, Shalinitai Meghe Hospital and Research Centre, (DMIMSU), Nagpur in collaboration with Jawaharlal Nehru Medical College, Datta Meghe Institute of Medical Sciences, Sawangi Meghe, Wardha, from October 2019 till March 2020 at tertiary care hospital and medical college. 70 antenatal patients were studied. Inclusion and exclusion criteria were laid for the patients.

\section{Inclusion criteria}

1. Singleton live foetus.

2. Cephalic presentation

3. Gestational age $>37 \mathrm{wks}$.

4. Bishop score $<=5$

5. Reactive NST

\section{Exclusion criteria}

1. Gestational age $<37$ wks.

2. Previous uterine surgery.

3. Abnormal presentation

4. Premature rupture of membranes.

5. Hypersensitivity to prostaglandin.

Patients fulfilling the inclusion criteria were included in the study. Data were collected from the hospital records. Dinoprostone gel containing $0.5 \mathrm{mg}$ prostaglandin E2 was used. After history taking and initial systemic examination per abdomen examination was done, per vaginum examination was done and bishop score was assessed. Prostaglandin E2 gel was introduced intracervically after taking written informed consent.

Procedure for PGE2 gel insertion -- after emptying the bladder patient is allowed to lie down supine in the lithotomy position. The tip of the prefilled syringe is placed intracervically and the gel is deposited just below the internal cervical os. After application, the woman remains reclined for at least 30 minutes.
Patients were monitored for vital parameters, fetal heart rate, uterine activity, and progress of labour. Vitals were recorded hourly. Fetal heart sounds were monitored half-hourly. Per vaginal examination was done every 6 hours and bishops score assessed. If bishop score is favourable i.e. 6 or above, repeat dose was avoided. The patient was observed for spontaneous progress of labour and if required augmentation with oxytocin was done according to titration method till 3 contractions in 10 minutes were reached. Partograph was charted for active labour. If after 24 hours cervix was unfavorable i.e. 5 or less then repeat dose of cerviprime was used. Maximum 2 doses of PGE2 gel were used. Those requiring a single dose of PGE2 gel were grouped as group 1 and those requiring reinstallation were grouped as group 2 .

\section{Observations and results}

Out of 70 patients, group 1 had 56 patients requiring single dose of dinoprostone gel and group 2 had 14 patients requiring second dose of induction.

For induction the mean gestational age was 39.02 weeks. At the time of induction the mean age was 24.8 years.

The common indications for induction of labour were postdatism (45.71\%), pregnancy induced hypertension $(21.42 \%)$ and intrauterine growth retardation (12.85\%)

Table 1: Shows indications of LSCS

\begin{tabular}{lccc} 
LSCS INDICATIONS & GROUP $_{1}$ & GROUP 2 & OVERALL \\
POST DATISM & $44.64 \%$ & $50 \%$ & $45.71 \%$ \\
PIH & $17.14 \%$ & $21.42 \%$ & $21.42 \%$ \\
IUGR & $14.28 \%$ & $7.14 \%$ & $12.85 \%$ \\
OTHERS & $19.64 \%$ & $21.42 \%$ & $20 \%$ \\
\hline
\end{tabular}

As seen from the table in both the groups the most common indication was post datism, followed by pregnancy-induced hypertension. While in group 1 the percentage was $44.64 \%$, in group 2 it was almost $50 \%$.

The mean bishop score at the time of induction was 1.9. The mean bishop score at 6 hours and 12 hours was compared in both groups.

Table 2: Shows Bishop score mean

\begin{tabular}{lccc} 
HOURS AFTER IOL & GROUP 1 & GROUP 2 & $\begin{array}{c}\text { OVERALL } \\
\text { MEAN }\end{array}$ \\
O HOURS & 2.2 & 1 & 1.9 \\
6 HOURS & 6.21 & 2.5 & 5.4 \\
12 HOURS & 9.26 & 3 & 8.01 \\
\hline
\end{tabular}

The improvement in mean bishops score at 6 and 12 hours in group 2 is just 2 as compared to 7.02 in group 1, 
The mean duration of the latent phase in group 1 and group 2 was 12.34 hours and 28. 25 hours respectively. Mean induction delivery time was 17.52 hours and 37.17 hours respectively in group 1 and group 2 .

Table 3: shows induction delivery time in hours

\begin{tabular}{|c|c|c|c|c|c|}
\hline & \multicolumn{2}{|c|}{ Group 1} & \multicolumn{2}{|c|}{ Group 2} & \multirow{2}{*}{$\begin{array}{l}\text { Overall } \\
\text { Mean }\end{array}$} \\
\hline & Mean & Range & Mean & Range & \\
\hline $\begin{array}{l}\text { Duration } \\
\text { of Latent } \\
\text { Phase }\end{array}$ & $\begin{array}{l}12.34 \\
\text { hours }\end{array}$ & & $\begin{array}{l}28.25 \\
\text { hours }\end{array}$ & & 18. 56 hours \\
\hline $\begin{array}{l}\text { Induction } \\
\text { Delivery } \\
\text { Time }\end{array}$ & $\begin{array}{l}17.52 \\
\text { hours }\end{array}$ & $\begin{array}{c}\text { 8-28 } \\
\text { hours }\end{array}$ & $\begin{array}{c}37.17 \\
\text { hours }\end{array}$ & $\begin{array}{l}32-40.5 \\
\text { hours }\end{array}$ & 21.45 hours \\
\hline
\end{tabular}

$51.78 \%$ patients required augmentation and $48.21 \%$ went in spontaneous labour in group 1 and $78.57 \%$ patients required augmentation and $21.42 \%$ went in spontaneous labour in group 2. Patients requiring augmentation were more in group 2.

The total incidence of vaginal delivery was $74.28 \%$, with $78.57 \%$ in group 1 and $74.28 \%$ in group 2 . The incidence of lower segment caesarean section was $25.71 \%$ with $21.42 \%$ in group 1 and $42.85 \%$ in group 2 .

Table 4: Shows mode of delivery

\begin{tabular}{lccc} 
& Group 1 & Group 2 & Overall \\
VAGINAL BIRTH & $44(78.57 \%)$ & $8(57.14 \%)$ & $52(74.28 \%)$ \\
LSCS & $12(21.42 \%)$ & $6(42.85 \%)$ & $18(25.71 \%)$ \\
\hline
\end{tabular}

The common indications of lower segment caesarean section were fetal distress, arrest in the progress of labour. The incidence of lower segment caesarean section was more in group 2 .

The mean birth weight was $2.68 \mathrm{~kg}$. Mean apgar at 1 minute was 7 and at 5 minutes were 9.2 babies were admitted in NICU. There was no neonatal death.

The common complications that occurred were vomiting (7.14\%), diarrhea (5.71\%).

3 patients had atonic postpartum haemorrhage, and 2 patients had traumatic postpartum haemorrhage. No serious complications happened.

\section{DISCUSSION}

Continuing a woman's pregnancy allows her cervix to remain closed, and her uterus to remain relaxed. There is a need to reverse both of these conditions to initiate labour. Cervix includes a small smooth muscle and mainly connective tissue with collagen as its key component and it must become soft and pliable. Prostaglandins play an significant role in the process of cervical maturation and labour initiation.

Throughout pregnancy and delivery, the fetal membranes and the decidua contain PGE2. PGE2 changes cervical biochemistry and also stimulates PGF $2 \alpha$. PGF $2 \alpha$ in effect sensitizes oxytocin to the myometrium. Exogenous PGE2 (Dinoprostone) administration is considered to imitate this natural cycle and contributes to cervical maturation or labor. ${ }^{6}$

In this study, the mean bishop score improvement was 3.5 at 6 hours and 6.2 at 12 hours Multiple studies showed an increase in bishop score varying from 3-7 7,8 . The mean score for the Bishop was 5.4 at 6 hours which is equivalent to the Noah et al. 1987 sample. $^{8}$

The mean average production time for the induction was 21.45 hours. Various studies have shown significant variability in the induction delivery period ranging from 9 hours Noah et al. 8 to 20.2 hours in a study performed by Jackson Gm 1994 9. In our study, the mean induction delivery time was greater in group 2 than in group 1 .

In our sample, the frequency of caesarean rate was 21.45 percent while in Warke et al. ${ }^{10}$ sample it was 16.67 percent. The prevalence of caesarean section cited in foreign literature ranged from 6 to 26.66 percent to 10 percent. In our sample the prevalence of caesarean section was greater in group 2 .

In this study, the number of babies admitted in NICU was 2 with no neonatal death while in a study done by Kavita et al. significant number of babies required NICU admission with PGE2 gel, though there was no particular mention regarding the number of doses. ${ }^{11}$

\section{CONCLUSION}

PGE2 GEL is a safe and efficient labor-induction process. The effectiveness of induction depends on the state of the cervix. This raises vaginal delivery chances without increasing maternal and neonatal morbidity.

Acknowledgement: Authors acknowledge the immense help received from the scholars whose articles are cited and included in references of this manuscript. The authors are also grateful to authors / editors / publishers of all those articles, journals and books from where the literature for this article has been reviewed and discussed.

\section{Conflict of interest: None}

\section{Source of Funding: Nil}

\section{REFERENCES}

1. K. F. Trofatter, "Cervical Ripening," Clinical Obstetrics abd Gynecology, Vol. 35, No. 3, 1992, pp. 476-486. doi:10.1097/00003081-199209000-00007 [Citation Time(s):1] 
2. J. E. Stempel, R. P. Prins and S. Dean, "Preinduction Cervical Ripening: A Randomized Prospective Comparison of the Efficacy and Safety of Intravaginal and Intracervical Prostaglandin E2 Gel," American Journal of Obstetrics \& Gynecology, Vol. 176, No. 6, 1997, pp. 1305-1312. doi:10.1016/S00029378(97)70350-8 [Citation Time(s):1]

3. Calder AA. Pharmacological management of the unripe cervix in the human. In: Naftolin F, Stubblefield PG, editors. Dilatation of the uterine cervix. New York: Ravin Press; 1980, pp 317-333.

4. Uldbjerg N, Ekman G, Malmstrom A. Ripening of the human uterine cervix related to changes in collagen, glycosaminoglycans and collagenolytic activity. Am J Obstet Gynecol 1983; 147:662-666.

5. Von Maillot K, Stunhlsatz HW, Mohanaradhakrishnan V. Changes in glycosominoglycan distribution in the human uterine cervix during pregnancy and labour. Am J Obstet Gynecol 1979; 135:503-506.

6. Induction of Labour. Evidence based clinical guideline No 9.2001
7. Prins RP, Bolton RN, Mark C. Cervical ripening with intravaginal prostaglandin E2 gel. Obstet Gynecol 1984; 63: 697-702.

8. Noah ML, Decoster JM, Fraser W. Preinduction cervical softening with endocervical PGE2 gel. A multicenter trial. Acta Obstet Gynecol scand 1987; 66: 3-7.

9. Jackson GM, Sharp HT, Varner MW. Cervical Ripening before induction of labour: a randomized trial of prostaglandin E2 gel versus low dose oxytocin. AMJ Obstet Gynecol 1994; 171 (4): 1092-6.

10. Warke H S, Saraogi R M, Sanjwalla S M. Prostaglandin E2 gel In ripening of cervix in induction of labour. J Postgrad Med 1999; 45:105.

11. Kavita A, Achla B, Aruna B, Abha A. Randomized comparison of isosorbide mononitrate and pge2 gel for cervical ripening at term including high risk pregnancy. International Journal of Reproductive Medicine. 2014;147274-9. 